\title{
A review of sleep disturbances following traumatic brain injury
}

\author{
José Rafael P. Zuzuárregui ${ }^{*}$, Kevin Bickart ${ }^{2}$ and Scott J. Kutscher ${ }^{3}$
}

\begin{abstract}
Background: Sleep disorders are common following traumatic brain injury (TBI).

Methods: We review the literature regarding sleep disturbances in the acute and chronic phase following TBI in both the adult and pediatric population.

Results: Acute and chronic disruption of sleep commonly follows TBI and contributes to morbidity commonly seen post-injury in both adults and children. This includes the direct effect of TBI leading to sleep disruption, as well as sleep disorders resulting from TBI itself. Pre-TBI neurocognitive testing is important to determine a baseline prior to injury, while disrupted sleep can also prolong recovery after TBI. Early recognition of sleep disturbances post-injury can lead to earlier treatment and limit the sequelae of TBI, as well as assist in recovery.

Conclusion: We suggest that evaluation for sleep disturbances following TBI is a critical component of post-TBI assessment and management.

Keywords: Traumatic brain injury, Sleep disturbances, Insomnia, Hypersomnia, Obstructive sleep apnea, Circadian rhythm sleep disorder
\end{abstract}

\section{Background}

Subjective sleep disturbances and objective sleep disorders following traumatic brain injury (TBI) are common issues encountered in clinical practice. TBI is defined as an injury that includes transient amnesia, alteration or loss of consciousness that results from a force involving the head or body (Wickwire et al. 2016; Mathias and Alvaro 2012). TBI can be classified as mild, moderate or severe based on the presence and severity of the above symptoms, as well as neuroimaging characteristics. Reportedly, up to 1.7 million Americans suffers TBI yearly, with $70 \%$ of those deemed mild (Wickwire et al. 2016; Mathias and Alvaro 2012). Of those who sustain TBI, recent estimates suggest that $30-66 \%$ of patients experience some type of sleep disturbance (Wickwire et al. 2016; Mathias and Alvaro 2012; Nakase-Richardson et al. 2013; Chan and Feinstein 2015). Sleep disturbances in post-TBI patients can present acutely or can emerge as a chronic issue during the recovery phase, occasionally lasting years

\footnotetext{
* Correspondence: rafzuzu@bu.edu

${ }^{1}$ Division of Neurology, University of California, San Francisco, Fresno Center for Medical Education and Research, 155 N. Fresno St., Fresno 93701, CA, USA

Full list of author information is available at the end of the article
}

from the initial injury (Wickwire et al. 2016). Sleep disturbances and resultant sleep disorders can also impair the recovery process from TBI. Sleep disorders reported in post TBI patients include insomnia and hypersomnia syndromes, circadian rhythm disorders, and sleep related breathing disorders.

Recently, Mollayeva, et al. discussed the possible mechanisms of sleep disturbances following TBI (Mollayeva et al. 2016). These mechanisms are beyond the scope of this review, but may include disruption of neuronal networks involved in wakefulness and sleep directly related to acceleration-deceleration injuries to these axons, as well as direct injury to structures responsible for regulation of the circadian rhythm (Wickwire et al. 2016; Mollayeva et al. 2016). Genetic susceptibility to circadian rhythm disorders, changes in sleep duration, and changes in sleep architecture also appears to play a role in the individual risk of development of sleep disruption following TBI. Craniofacial anatomy prior to TBI also appears to predispose the individual to development of sleep-disordered breathing (Mollayeva et al. 2016). 
As a result, patients may experience a variety of sleep disturbances following TBI that emerge at different postinjury intervals (Table 1 ).

Previous studies have delineated TBI into the following time frames: acute phase occurring from 0 to 7 days, subacute phase occurring between 7 and 90 days, and chronic phase occurring greater than 90 days (Wickwire et al. 2016; Mollayeva et al. 2016). However, there is no current consensus on what constitutes these time frames as it relates to the emergence of sleep disturbances following TBI. The acute phase for sleep disruption has been described as occurring anywhere from 1 week up to one year post-injury, while the chronic phase has been felt to begin six months to a year following TBI (Wickwire et al. 2016; Nakase-Richardson et al. 2013; Chan and Feinstein 2015; Mollayeva et al. 2016; Pillar et al. 2003; Baumann et al. 2007; Sommerauer et al. 2013; Raikes and Schaefer 2016; Watson et al. 2007; Imbach et al. 2015). In this review, we designate the acute phase up to six months post-injury, with the chronic phase six months or greater.

Those who sustain TBI may suffer from hypersomnia and insomnia in the acute period post-injury (Wickwire et al. 2016; Baumann et al. 2007; Sommerauer et al. 2013; Raikes and Schaefer 2016; Watson et al. 2007; Imbach et al. 2015). Furthermore, central nervous system symptoms occurring as a result of TBI also may cause disruption of sleep (Pillar et al. 2003; Lavigne et al. 2015; Chaput et al. 2009; Minen et al. 2016; Hou et al. 2013; Jaramillo et al. 2016; Farrell-Carnahan et al. 2015; Bryan 2013; Holster et al. 2017). These include headache, tinnitus and/or vertigo. Mood disorders such as anxiety or depression that result from TBI are also common and may have a negative impact on sleep (Pillar et al. 2003; Chaput et al. 2009; Minen et al. 2016; Farrell-Carnahan et al. 2015; Bryan 2013; Holster et al. 2017). Sleep disturbances in the chronic phase are varied and include insomnia as well as circadian rhythm disruption (Wickwire et al. 2016; Mathias and Alvaro 2012; Nakase-Richardson

Table 1 Sleep Disturbances Following TBI in the Acute and Chronic Phase

\begin{tabular}{ll}
\hline Time period & Diagnosis \\
\hline Acute & Hypersomnia \\
& Insomnia related to post-traumatic headache \\
& Insomnia related to post-traumatic mood disturbance \\
& Insomnia \\
Chronic & Insomnia \\
& Circadian rhythm disorders \\
& Obstructive sleep apnea \\
& Narcolepsy \\
& Chronic Traumatic Encephalopathy
\end{tabular}

et al. 2013; Chan and Feinstein 2015; Mollayeva et al. 2016; Pillar et al. 2003). In addition, the development of obstructive sleep apnea (OSA) and narcolepsy has also been described following TBI (Wickwire et al. 2016; Mathias and Alvaro 2012; Nakase-Richardson et al. 2013; Chan and Feinstein 2015; Mollayeva et al. 2016; Pillar et al. 2003). Here, we review commonly encountered sleep disturbances following TBI.

\section{Methods}

Two authors (JZ and KB) independently searched the international literature through February 2, 2017 for articles evaluating sleep disturbances following TBI, as well as the impact of sleep on cognition. Databases searched included PubMED/Medline and The Cochrane Library. The inclusion criteria: studies evaluating sleep disturbances in both adults and pediatric populations following TBI itself or direct sequelae resulting from TBI, as well as the impact of sleep on cognition. This includes the impact of sleep on neurocognitive testing in groups at high risk for TBI. An example of a search performed in PubMED/Medline is: "sleep"[MeSH Terms] OR “sleep"[All Fields]) AND ("brain injuries, traumatic"[MeSH Terms] OR ("brain"[All Fields] AND "injuries"[All Fields] AND "traumatic"[All Fields]) OR "traumatic brain injuries"[All Fields] OR ("traumatic"[All Fields] AND "brain"[All Fields] AND "injury"[All Fields]) OR "traumatic brain injury"[All Fields]). There was no language restriction.

\section{Sleep disturbances in the acute period following TBI Hypersomnia}

Increased sleep need is a significant issue in the acute period following TBI (Baumann et al. 2007; Sommerauer et al. 2013; Raikes and Schaefer 2016). A prospective study of 96 patients with TBI demonstrated that $22 \%$ experienced hypersomnia following TBI, defined as a sleep need of equal to or greater than $2 \mathrm{~h}$ when compared to pre-TBI sleep need (Baumann et al. 2007). Although no correlations were noted with regards to cerebrospinal fluid (CSF) hypocretin levels, polysomnography (PSG) or multiple sleep latency tests (MSLT), post-TBI patients reporting hypersomnia suffered more severe TBI than those without (Baumann et al. 2007). A retrospective case-control study $(n=36)$ showed that patients with hypersomnia based initially on actigraphy testing demonstrated increased stage 3 sleep on subsequent PSG testing when compared to controls (Sommerauer et al. 2013).

While it is clear that hypersomnia affects a significant number of patients following TBI, the length of time that this persists is variable. A recent prospective study $(n=17)$ used actigraphy to demonstrate that an increased sleep need might be seen in the acute period following 
TBI, resolving one month post-injury (Raikes and Schaefer 2016). A larger prospective study $(n=748)$ showed that these changes persist up to one month, but may resolve by one year following TBI; however, increased sleep need was assessed via survey rather than actigraphy (Watson et al. 2007). Finally, a case-control study evaluating 42 patients with first-time TBI showed that sleep need was still significantly increased at 6 months when compared to controls (Imbach et al. 2015). The development of hypersomnia following TBI is a significant predictor of negative social outcomes, including subjective difficulties for patients at work, in relationships and various social settings (Chan and Feinstein 2015). This highlights the need for early assessment and treatment of hypersomnia.

\section{Insomnia due to post-traumatic headache}

Headache following TBI is a common symptom seen in $20-46.8 \%$ of patients with TBI $(n=443)$ (Lavigne et al. 2015; Chaput et al. 2009). This symptom can have a significant impact on quality of life both during wakefulness and sleep and can be seen irrespective of the severity of the injury. Multiple studies have been performed to evaluate the impact of post-traumatic headache (PTH) on sleep, with insomnia the most common symptom experienced (Minen et al. 2016; Hou et al. 2013). A retrospective cohort study $(n=98)$ showed that headache and insomnia are frequently comorbid conditions in the mild TBI population, with up to half of patients with PTH also suffering from insomnia (Hou et al. 2013). This study also showed that PTH portended a higher risk of development of insomnia when compared to severity of TBI, with estimates from 12.5 to 27\% (Hou et al. 2013; Jaramillo et al. 2016). Finally, multiple studies have shown that insomnia appears to predict the persistence of PTH in TBI patients, leading to a vicious cycle where each symptom promotes the presence of the other. (Chaput et al. 2009; Hou et al. 2013).

\section{Insomnia due to post-traumatic mood disturbances}

Mood disturbances following TBI are also common, with estimates of prevalence of depression from 20 to $46 \%$ and anxiety from 24 to $61 \%(n=443)$ (Chaput et al. 2009; Minen et al. 2016; Jaramillo et al. 2016). Depression and anxiety are often comorbid with PTH following TBI, with up to $33 \%$ of patients with TBI suffering from a mood disturbance and PTH (Minen et al. 2016). In addition, one study of 150 subjects and another of 168 subjects demonstrated that patients with TBI previously who suffered a repeat TBI were at higher risk for development of depression than those without previous TBI (Bryan 2013; Holster et al. 2017). Frequently, these patients often have poor sleep due to insomnia, with multiple studies demonstrating an increased association with depression and anxiety (Chaput et al. 2009; Minen et al. 2016; Farrell-Carnahan et al. 2015; Bryan 2013; Holster et al. 2017). One review showed that the presence of insomnia in patients with TBI has a risk of depression six times higher than those who have suffered TBI without insomnia (Minen et al. 2016).

\section{Insomnia}

Insomnia has been demonstrated in the acute phase following TBI, with patients reporting difficulty in both initiation and maintenance of sleep (Chan and Feinstein 2015; Pillar et al. 2003; Lavigne et al. 2015; Chaput et al. 2009; Minen et al. 2016; Jaramillo et al. 2016). As noted above, this insomnia is typically seen comorbid with post-traumatic headache and mood disturbances (Lavigne et al. 2015; Chaput et al. 2009; Minen et al. 2016; Jaramillo et al. 2016). Some studies have suggested that insomnia is not independent of these issues following TBI, given the significant interaction between pain, depression and anxiety on sleep disturbance (Chan and Feinstein 2015; Lavigne et al. 2015; Chaput et al. 2009; Minen et al. 2016; Jaramillo et al. 2016). Further studies need to be performed to separate this interaction and define the true prevalence of acute insomnia development in the absence of post-traumatic symptoms.

\section{Sleep disturbances in the chronic period following TBI}

Insomnia

Insomnia is also a chronic issue following TBI. The prevalence of insomnia following TBI is varied, with anywhere from 10 to $84 \%$ of patients reporting insomnia symptoms up to three years following injury (Chan and Feinstein 2015; Mollayeva et al. 2016; Pillar et al. 2003; Hou et al. 2013; Ouellet et al. 2006; Viola-Saltzman and Musleh 2016; Zeitzer et al. 2009; Kempf et al. 2010). One small prospective study, however, found insomnia occurring in only three of 65 patients using actigraphy and PSG (Baumann et al. 2007).

The true prevalence of insomnia has been called into question as some studies have shown an overestimation of insomnia reported by patients with TBI when evaluated with subjective questionnaires and PSG (Ouellet and Morin 2006; Lu et al. 2015). While this may be an important consideration, other studies have used PSG to demonstrate increased sleep latency in patients with TBI, in addition to reduced sleep efficiency and increased sleep fragmentation (Ouellet and Morin 2006; Lu et al. 2015; Parcell et al. 2008; Williams et al. 2008).

Insomnia also appears to be an issue that may also worsen comorbid conditions related to TBI. As noted above, patient with insomnia following TBI are not only are at risk for development of PTH and post-traumatic mood disturbances, but the presence of these co-morbid problems can disrupt sleep and worsen insomnia symptoms 
(Lavigne et al. 2015; Chaput et al. 2009; Minen et al. 2016; Hou et al. 2013; Jaramillo et al. 2016; Farrell-Carnahan et al. 2015).

\section{Circadian rhythm disorders}

Circadian rhythm disorders following TBI have not been well described in humans, with most early reports being case studies (Nagtegaal et al. 1997; Smits et al. 2000; Quinto et al. 2000). One study evaluated patients with insomnia following TBI with the use of actigraphy, saliva melatonin measurements, and body temperature measurement for the presence of a circadian rhythm sleep disorder (Ayalon et al. 2007). Of 42 patients in this study, $36 \%$ demonstrated evidence of either a delayed or advanced circadian rhythm. A recent study $(n=18)$ demonstrated that patients with TBI produced $42 \%$ less melatonin overnight when compared to controls, in addition to a delay in dim light melatonin onset by approximately $1.5 \mathrm{~h}$ (Grima et al. 2016). Another study $(n=46)$ showed that evening melatonin production is significantly lower in patients with TBI at least one year following injury when compared to controls (Shekleton et al. 2010). Although these studies clearly show a variability in the timing of melatonin production, it is unclear whether this finding is related to damage of intrinsic melatonin production or simply a change in circadian rhythm from TBI. In addition, these studies are unable to determine if circadian rhythm changes occurred after TBI as they did not evaluate patients prior to TBI.

\section{Obstructive sleep apnea}

The role of TBI in the development of obstructive sleep apnea (OSA) has been the subject of some debate. Some studies have shown that OSA appears to increase the risk of TBI, while other studies suggest that OSA is diagnosed more frequently post-injury. The etiology behind this finding is unclear, but may be related to craniofacial anatomy that places the patient at risk for subsequent development of OSA after TBI (Mollayeva et al. 2016). In one study $(n=87)$ that evaluated the prevalence of sleep disorders following TBI, PSG performed at three months post-injury demonstrated $23 \%$ of those with TBI had comorbid OSA (Castriotta et al. 2007). However, no baseline data was performed for comparison of OSA rates prior to TBI. A study by Guilleminault, et al. showed that $32 \%$ of patients $(n=184)$ with TBI were diagnosed with OSA post-injury (Guilleminault et al. 2000). However, the authors acknowledged that OSA may have been present in several patients prior to TBI. Several other studies evaluating the presence of OSA following TBI, found prevalence rates ranging from 11 to 61\% (Wickwire et al. 2016; Mathias and Alvaro 2012; Baumann et al. 2007; Castriotta et al. 2007; Masel et al. 2001; Collen et al. 2012). In most cases, pre-TBI testing with PSG was not available to confirm or rule out the presence of OSA prior to injury.

Nevertheless, recognition of OSA in patients with TBI is important due to the negative impact that it may have on cognition, which may be negatively impacted due to TBI itself.

\section{Narcolepsy}

Narcolepsy following TBI has been the subject of debate for many years, with the overall prevalence of narcolepsy following TBI estimated from 3 to 6\% (Castriotta et al. 2007; Masel et al. 2001). While a CSF hypocretin deficiency has been noted in the acute post-injury period, normalization of these levels has also been found in a number of patients over time. One study demonstrated recovery of hypocretin levels to normal levels six months post-injury in 17 of 21 patients with EDS, while another study $(n=27)$ demonstrated that $19 \%$ of patients with narcolepsy without cataplexy developed symptoms within two years of suffering TBI (Baumann et al. 2007; Poryazova et al. 2011). Furthermore, pathologic examination of patients with severe TBI $(n=44)$ showed only mild damage to specific hypocretin neurons, while more widespread damage was seen in hypothalamic neurons involved in sleep-wake regulation (Baumann et al. 2005; 2009). Subsequently, the development of hypocretin deficient narcolepsy is questionable given the lack of specificity in damage to hypocretin neurons, as well as inconsistent presentation with regards to CSF hypocretin levels in hypersomnolence post TBI patients (Baumann et al. 2005). This is further reinforced by the demonstration of one such patient with narcolepsy following TBI in whom diffuse tensor imaging demonstrated injury to the ascending reticular activating system between the pons and hypothalamus, rather than the hypothalamus itself (Jang et al. 2016). The pathophysiology behind development of narcolepsy in post-TBI patients is likely of heterogeneous etiologies, and appears to differ from narcolepsy type I.

Despite the potential differences in pathophysiology, many post TBI patients appear to develop hypersomnolence consistent with that seen in type II narcolepsy. In contrast, very few patients appear to experience cataplexy as part of their symptomatology (Baumann et al. 2007). One study $(n=37)$ evaluated a group of patients with TBI who were HLA DQB1*0602 positive and found that seven patients (19\%) developed narcolepsy with cataplexy after TBI (Poryazova et al. 2011). The authors suggested that these patients were genetically predisposed to the development of narcolepsy with cataplexy prior to TBI rather than cataplexy developing from TBI itself. Diagnostic testing with PSG and MSLT is often positive in patients with narcolepsy following TBI, with most studies using criteria of mean sleep latency $<5 \mathrm{~min}$ and $\geq 2$ sleep onset rapid 
eye movement periods (Baumann et al. 2007; Castriotta et al. 2007; Poryazova et al. 2011; Jang et al. 2016). In light of these contrasting findings, it would seem that the use of PSG and MSLT for diagnosis for narcolepsy would be a more consistent diagnostic tool than use of CSF hypocretin levels.

\section{Chronic traumatic encephalopathy}

The recent discovery of chronic traumatic encephalopathy (CTE) has led to significant interest in research regarding this disease over the past fifteen years. CTE refers to a unique set of pathologic changes in the central nervous system that develop following traumatic brain injury, including a perivascular distribution of tau-positive neurofibrillary tangles in the neocortex (McKee et al. 2009). While CTE can have a significant impact on the neurocognitive profile of patients, as well as lead to neurodegeneration, literature regarding the impact of CTE on sleep is sparse (McKee et al. 2009). Although there has been some suggestion that OSA and insomnia may be risk factors for development of CTE, it is clear that poor sleep can negatively impact symptoms commonly seen in CTE, such as aggression, impulsivity and poor cognition (Quan 2014; Asken et al. 2016). At this time, research efforts have been sparse and have yet to elucidate the potential impact of sleep on the development of CTE.

\section{Special considerations in the pediatric population}

Even fewer investigations into sleep disturbances following TBI have been performed in the pediatric population, though interest has increased recently. Recent reviews of sleep disturbances in pediatric patients following TBI demonstrated that most studies focused on adolescents and used subjective measures to evaluate symptoms (Gagner et al. 2015; Hung et al. 2014; Beebe et al. 2007). However, sleep disturbances were common post-injury and included excessive daytime sleepiness, increased sleep latency and circadian rhythm disruption, though the latter was not as common (Gagner et al. 2015). One such prospective study of 15 patients demonstrated that sleep onset and maintenance difficulties were significantly increased in the TBI group when compared to their siblings (Sumpter et al. 2013). A similar recent prospective study evaluated 100 adolescent patients three to twelve months following TBI for sleep disturbances using questionnaires and actigraphy (Tham et al. 2015). Following TBI, patients not only reported poor sleep quality, but were also shown to have a shorter sleep duration and poorer sleep efficiency when compared to controls (Tham et al. 2015). This finding is in contrast to a previous study from the same authors $(n=926)$ that showed sleep disturbances were not significantly persistent three months post-injury (Tham et al. 2012). Despite recent interest, the dearth of information regarding sleep in pediatric TBI highlights the need for further research in this population.

\section{Sleep and Neurocognition}

Neurocognitive deficits are a well-known and disabling feature of TBI. As a result, neuropsychological testing has become a mainstay of post-injury evaluation. Various studies have revealed deficits in multiple neurocognitive domains following TBI, such as attention, visuospatial ability, memory and executive function (Carlsson et al. 1987; Konrad et al. 2011; Ponsford et al. 2008; De Beaumont et al. 2009; Himanen et al. 2006; Isoniemi et al. 2006; Monti et al. 2013). Others have demonstrated the utility of post-injury neuropsychological testing in predicting which patients develop chronic neurocognitive impairments (Carlsson et al. 1987; Konrad et al. 2011; Ponsford et al. 2008; De Beaumont et al. 2009; Himanen et al. 2006; Isoniemi et al. 2006; Monti et al. 2013). One such study $(n=105)$ showed that cognitive flexibility and reaction times testing in the emergency department predicted symptoms one month following TBI in the pediatric population (Brooks et al. 2016). Another study $(n=61)$ demonstrated that older age and male sex portended a higher risk of developing chronic deficits in visuospatial ability and visual memory (Himanen et al. 2006). Others have shown that repeated TBI, rather than age, was the major risk factor for permanent deficits (Carlsson et al. 1987).

While factors such as age, severity of trauma, number of prior traumatic brain injuries and timing of prior TBI have been shown to impact the outcome of neurocognitive testing, few studies have evaluated the impact of sleep on recovery (Albrecht et al. 2016; Gaudet and Weyandt 2017; Martindale et al. 2017; Lau et al. 2011; Sufrinko et al. 2015; Singh et al. 2016). Of these, one study $(n=348)$ demonstrated that patients with insomnia and reduced sleep times prior to TBI have a prolonged recovery post-injury as measured by the Immediate Post-concussion Assessment and Cognitive Test and Post-concussion Symptom Scale when compared to controls (Sufrinko et al. 2015). Another study demonstrated that poor sleep quality independently predicted cognitive dysfunction in post-TBI combat veterans when controlling for other variables such as PTSD, while others have corroborated that poor sleep prolonged cognitive recovery from TBI in non-combat patients (Martindale et al. 2017; Singh et al. 2016). Furthermore, sleep disturbances prior to TBI also increase the risk of postconcussive symptoms, which negatively impacts sleep and further contributes to prolonged recovery (Chan and Feinstein 2015; Lavigne et al. 2015; Chaput et al. 2009; Minen et al. 2016; Jaramillo et al. 2016; Singh et al. 2016).

Recently, a small group of studies have demonstrated the impact of various sleep metrics in the assessment of 
neurocognitive testing in TBI at baseline. One such study $(n=144)$ showed that athletes with low selfreported sleep quantity (68\% of the subject's normal sleep quantity) performed worse on baseline neurocognitive testing than those with moderate (90\%) or high sleep quantity (110\%) (Mihalik et al. 2013). A subsequent study $(n=3686)$ showed that athletes without previous history of TBI with less than $7 \mathrm{~h}$ of sleep time prior to baseline neurocognitive testing had lower scores than those with more than $7 \mathrm{~h}$ of sleep (McClure et al. 2014).

Given the impact of poor sleep on baseline testing, sleep patterns prior to TBI should be considered by physicians when ordering or interpreting baseline neurocognitive testing. Postponement of neurocognitive testing should be considered if patients report a poor prior night of sleep. Finally, the development of sleep disturbances following TBI should be evaluated for and addressed in a timely fashion to improve recovery post-injury.

\section{Treatment}

Recovery from TBI can be negatively impacted by the aforementioned sleep disorders, highlighting the need for treatment of these conditions as they arise. Investigation into treatment of specific sleep disorders resulting from TBI, however, has been limited and largely based on current standard of care (Wickwire et al. 2016; Castriotta et al. 2009; Menn et al. 2014; Al-Adawi et al. 2006; Mignot 2012; Rao et al. 2015). For hypersomnia resulting from TBI, one randomized controlled trial $(n=117)$ showed that armodafinil $250 \mathrm{mg}$ significantly reduced daytime sleepiness on Epworth Sleepiness scale and longer sleep latency on PSG (Menn et al. 2014). Methylphenidate did not show a significant impact on number of hours of sleep in TBI patients when compared to placebo $(n=30)$ (Al-Adawi et al. 2006). We recommend use of armodafinil and modafinil, but more potent stimulants may need to be used (Castriotta et al. 2009; Mignot 2012). Treatment of insomnia in TBI can be particularly challenging due to the comorbid conditions that arise from TBI itself and their respective impact sleep quality. Use of antidepressants for post-TBI mood disturbances is common, but the impact of these medications on cognitive recovery is not well studied (Rao et al. 2015). Agents with anticholinergic or heavy sedative qualities can worsen cognition and should be avoided if possible (Rao et al. 2015). Cognitive behavioral therapy is first line therapy for treatment of insomnia, but has not been well-evaluated in patients with insomnia resulting from TBI (Wickwire et al. 2016). Nevertheless, we recommend this therapy as first-line, which may also be a useful adjunct therapy for treatment of mood disorders resulting from TBI (Wickwire et al. 2016). Benzodiazepine-like agonists, such as zolpidem, are commonly used for the treatment of insomnia in the TBI population (Wickwire et al. 2016; Management of Concussion/mTBI Working Group 2009). No randomized trials have evaluated the efficacy of these medications for insomnia following TBI. However, one study found that these medications may increase the risk of dementia in the TBI population, after controlling for the cognitive impact of insomnia (Chiu et al. 2015). If used at all, they should likely be limited to short term use. There are no trials that have explored melatonin in the treatment of circadian rhythm disorders due to TBI. One study showed that melatonin did not improve sleep latency, duration, or quality in this group (Kemp et al. 2004). In post-injury patients with OSA, we strongly recommend a trial of continuous positive airway pressure therapy to reduce the impact on sleep disordered breathing on cognition, which may already be impaired following TBI (Wickwire et al. 2016; Castriotta et al. 2009). Finally, treatment of narcolepsy resulting from TBI has not been wellstudied and has focused on hypersomnia in this group. Similar to the recommendations above, modafinil and armodafinil should be tried first (Castriotta et al. 2009; Mignot 2012).

\section{Conclusion}

The impact of sleep disturbances on quality of life is well documented, with a particularly negative impact in patients with TBI in terms of cognitive and functional recovery from TBI (Wickwire et al. 2016; Mathias and Alvaro 2012; Chan and Feinstein 2015; Duclos et al. 2015; Mollayeva et al. 2016). This can occur directly from the sleep disturbances resulting from TBI or from a secondary exacerbation of common symptoms seen post-injury, such as headache, pain, mood disturbances or cognitive decline (Wickwire et al. 2016; Lavigne et al. 2015; Chaput et al. 2009; Minen et al. 2016; Hou et al. 2013; Jaramillo et al. 2016; Farrell-Carnahan et al. 2015; Duclos et al. 2015; Mollayeva et al. 2016; Ouellet et al. 2015; Theadom et al. 2016). A notable decrease of independence in performing activities of daily living in the recovery from TBI has been shown in patients with sleep disturbances post-injury, portending functional difficulties in the recovery period (Wickwire et al. 2016; Duclos et al. 2015). In addition to this, sleep disturbances also appear to prolong recovery from TBI (Mollayeva et al. 2016; Ouellet et al. 2015; Theadom et al. 2016). For these reasons, assessment and treatment for sleep disturbances following TBI is paramount to assist in improving quality of life and recovery from TBI itself.

\section{Abbreviations}

CSF: Cerebrospinal fluid; CTE: Chronic traumatic encephalopathy; MSLT: Multiple sleep latency tests; OSA: Obstructive sleep apnea;

PSG: Polysomnography; PTH: Post-traumatic headache; TBI: Traumatic brain injury

\section{Acknowledgements}

The authors declare no acknowledgements. 


\section{Funding}

The authors declare there was no funding for this study.

\section{Availability of data and materials}

The authors declare that all studies referenced in this article can be found on PubMED/Medline.

\section{Authors' contributions}

JZ conceived of the study, participated in its design and coordination, performed a literature search and helped to draft the manuscript. KB performed a literature search and helped to draft the manuscript. SK conceived of the study, participated in its design and coordination, and helped to draft the manuscript. All authors read and approved the final manuscript.

\section{Ethics approval and consent to participate}

Not applicable

\section{Consent for publication}

Not applicable

\section{Competing interests}

The authors declare that they have no competing interests.

\section{Publisher's Note}

Springer Nature remains neutral with regard to jurisdictional claims in published maps and institutional affiliations.

\section{Author details}

'Division of Neurology, University of California, San Francisco, Fresno Center for Medical Education and Research, 155 N. Fresno St., Fresno 93701, CA, USA. ${ }^{2}$ Department of Neurology, Stanford University School of Medicine, Stanford, USA. ${ }^{3}$ Division of Sleep Medicine, Department of Psychiatry, Stanford University School of Medicine, Stanford, USA.

Received: 24 May 2017 Accepted: 8 February 2018

Published online: 16 February 2018

\section{References}

Al-Adawi S, Burke DT, Dorvlo AS. The effect of methylphenidate on the sleep-wake cycle of brain-injured patients undergoing rehabilitation. Sleep Med. 2006;7(3): 287-91.

Albrecht MA, Masters CL, Ames D, Foster JK, AIBL Research Group. Impact of mild head injury on neuropsychological performance in healthy older adults: longitudinal assessment in the AIBL cohort. Front Aging Neurosci. 2016;8:105.

Asken BM, Sullan MJ, Snyder AR, Houck ZM, Bryant VE, Hizel LP, McLaren ME, Dede DE, Jaffee MS, DeKosky ST, Bauer RM. Factors influencing clinical correlates of chronic traumatic encephalopathy (CTE): a review. Neuropsychol Rev. 2016;26(4):340-63.

Ayalon L, Borodkin K, Dishon L, Kanety H, Dagan Y. Circadian rhythm sleep disorders following mild traumatic brain injury. Neurology. 2007;68:1136-40.

Baumann CR, Bassetti CL, Valko PO, Haybaeck J, Keller M, Clark E, Stocker R, Tolnay M, Scammell TE. Loss of hypocretin (orexin) neurons with traumatic brain injury. Ann Neurol. 2009;66(4):555-9.

Baumann CR, Stocker R, Imhof HG, Trentz O, Hersberger M, Mignot E, Bassetti CL. Hypocretin-1 (orexin A) deficiency in acute traumatic brain injury. Neurology. 2005:65(1):147-9.

Baumann CR, Werth E, Stocker R, et al. Sleep-wake disturbances 6 months after traumatic brain injury: a prospective study. Brain. 2007:130:1873-83.

Beebe DW, Krivitzky L, Wells CT, Wade SL, Taylor HG, Yeates KO. Brief report: parental report of sleep behaviors following moderate or severe pediatric traumatic brain injury. J Pediatr Psychol. 2007;32(7):845-50.

Brooks BL, Daya H, Khan S, Carlson HL, Mikrogianakis A, Barlow KM. Cognition in the Emergency Department as a Predictor of Recovery after Pediatric Mild Traumatic Brain Injury. J Int Neuropsychol Soc. 2016;22(4):379-87.

Bryan CJ. Repetitive traumatic brain injury (or concussion) increases severity of sleep disturbance among deployed military personnel. Sleep. 2013;36(6):941-6.

Carlsson GS, Svärdsudd K, Welin L. Long-term effects of head injuries sustained during life in three male populations. J Neurosurg. 1987;67(2):197-205.

Castriotta RJ, Atanasov S, Wilde MC, Masel BE, Lai JM, Kuna ST. Treatment of sleep disorders after traumatic brain injury. J Clin Sleep Med. 2009;5(2):137-44.
Castriotta RJ, Wilde MC, Lai JM, Atanasov S, Masel BE, Kuna ST. Prevalence and consequences of sleep disorders in traumatic brain injury. J Clin Sleep Med. 2007;3(4):349-56

Chan LG, Feinstein A. Persistent sleep disturbances independently predict poorer functional and social outcomes 1 year after mild traumatic brain injury. Head Trauma Rehabil. 2015;30(6):E67-75.

Chaput G, Giguère JF, Chauny JM, Denis R, Lavigne G. Relationship among subjective sleep complaints, headaches, and mood alterations following a mild traumatic brain injury. Sleep Med. 2009;10(7):713-6.

Chiu HY, Lin EY, Wei L, Lin JH, Lee HC, Fan YC, Tsai PS. Hypnotics use but not insomnia increased the risk of dementia in traumatic brain injury patients. Eur Neuropsychopharmacol. 2015;25(12):2271-7.

Collen J, Orr N, Lettieri CJ, Carter K, Holley AB. Sleep disturbances among soldiers with combat-related traumatic brain injury. Chest. 2012;142:622-30.

De Beaumont L, Théoret H, Mongeon D, Messier J, Leclerc S, Tremblay S, Ellemberg D, Lassonde M. Brain function decline in healthy retired athletes who sustained their last sports concussion in early adulthood. Brain. 2009; 132(Pt 3):695-708.

Duclos C, Beauregard MP, Bottari C, Ouellet MC, Gosselin N. The impact of poor sleep on cognition and activities of daily living after traumatic brain injury: a review. Aust Occup Ther J. 2015:62(1):2-12.

Farrell-Carnahan L, Barnett S, Lamberty G, Hammond FM, Kretzmer TS, Franke LM, Geiss M, Howe L, Nakase-Richardson R. Insomnia symptoms and behavioural health symptoms in veterans 1 year after traumatic brain injury. Brain Inj. 2015;29(12):1400-8

Gagner C, Landry-Roy C, Lainé F, Beauchamp MH. Sleep-wake disturbances and fatigue after pediatric traumatic brain injury: a systematic review of the literature. J Neurotrauma. 2015:32(20):1539-52.

Gaudet CE, Weyandt LL. Immediate post-concussion and cognitive testing (ImPACT): a systematic review of the prevalence and assessment of invalid performance. Clin Neuropsychol. 2017;31(1):43-58.

Grima NA, Ponsford JL, St Hilaire MA, Mansfield D, Rajaratnam SM. Circadian melatonin rhythm following traumatic brain injury. Neurorehabil Neural Repair. 2016;30(10):972-7.

Guilleminault C, Yuen KM, Gulevich MG, Karadeniz D, Leger D, Philip P. Hypersomnia after head-neck trauma: a medicolegal dilemma. Neurology. 2000;54(3):653-9.

Himanen L, Portin R, Isoniemi $H$, Helenius $H$, Kurki T, Tenovuo O. Longitudinal cognitive changes in traumatic brain injury: a 30-year follow-up study. Neurology. 2006;66(2):187-92

Holster JL, Bryan CJ, Heron EA, Seegmiller RA. Traumatic brain injury, sleep, and mental health: a longitudinal study of air force personnel pre- and post deployment to Iraq. J Head Trauma Rehabil. 2017;32(1):25-33.

Hou L, Han X, Sheng P, Tong W, Li Z, Xu D, et al. Risk factors associated with sleep disturbance following traumatic brain injury: clinical findings and questionnaire based study. PLoS One. 2013;8(10):e76087.

Hung R, Carroll LJ, Cancelliere C, Côté P, Rumney P, Keightley M, Donovan J, Stålnacke BM, Cassidy JD. Systematic review of the clinical course, natural history, and prognosis for pediatric mild traumatic brain injury: results of the international collaboration on mild traumatic brain injury prognosis. Arch Phys Med Rehabil. 2014;95(3 Suppl):S174-91.

Imbach LL, Valko PO, Li T, Maric A, Symeonidou ER, Stover JF, Bassetti CL, Mica L, Werth E, Baumann CR. Increased sleep need and daytime sleepiness 6 months after traumatic brain injury: a prospective controlled clinical trial. Brain. 2015;138:726-35.

Isoniemi H, Tenovuo O, Portin R, Himanen L, Kairisto V. Outcome of traumatic brain injury after three decades-relationship to ApoE genotype. J Neurotrauma. 2006:23(11):1600-8.

Jang SH, Seo WS, Kwon HG. Post-traumatic narcolepsy and injury of the ascending reticular activating system. Sleep Med. 2016:17:124-5.

Jaramillo CA, Eapen BC, McGeary CA, McGeary DD, Robinson J, Amuan M, et al. A cohort study examining headaches among veterans of Iraq and Afghanistan wars: associations with traumatic brain injury, PTSD, and depression. Headache. 2016:56(3):528-39.

Kemp S, Biswas R, Neumann V, Coughlan A. The value of melatonin for sleep disorders occurring post-head injury: a pilot RCT. Brain Inj. 2004;18:911-9.

Kempf J, Werth E, Kaiser PR, Bassetti CL, Baumann CR. Sleep-wake disturbances 3 years after traumatic brain injury. J Neurol Neurosurg Psychiatry. 2010:81(12):1402-5.

Konrad C, Geburek AJ, Rist F, Blumenroth H, Fischer B, Husstedt I, Arolt V, Schiffbauer $\mathrm{H}$, Lohmann $\mathrm{H}$. Long-term cognitive and emotional consequences of mild traumatic brain injury. Psychol Med. 2011;41(6):1197-211. 
Lau BC, Collins MW, Lovell MR. Sensitivity and specificity of subacute computerized neurocognitive testing and symptom evaluation in predicting outcomes after sports-related concussion. Am J Sports Med. 2011;39(6):1209-16.

Lavigne G, Khoury S, Chauny JM, Desautels A. Pain and sleep in post-concussion/ mild traumatic brain injury. Pain. 2015;156(Suppl 1):S75-85.

Lu W, Cantor JB, Aurora RN, Gordon WA, Krellman JW, Nguyen M, Ashman TA, Spielman L, Ambrose AF. The relationship between self-reported sleep disturbance and polysomnography in individuals with traumatic brain injury. Brain Inj. 2015;29(11):1342-50

Management of Concussion/mTBI Working Group. VA/DoD clinical practice guideline for Management of Concussion/mild traumatic brain injury. J Rehabil Res Dev. 2009;46(6):CP1-68.

Martindale SL, Morissette SB, Rowland JA, Dolan SL. Sleep quality affects cognitive functioning in returning combat veterans beyond combat exposure, PTSD, and mild TBI history. Neuropsychology. 2017;31(1):93-104.

Masel BE, Scheibel RS, Kimbark T, Kuna ST. Excessive daytime sleepiness in adults with brain injuries. Arch Phys Med Rehabil. 2001;82:1526-32.

Mathias $J$, Alvaro PK. Prevalence of sleep disturbances, disorders, and problems following traumatic brain injury: a meta-analysis. Sleep Med. 2012;13(7):898-905.

McClure DJ, Zuckerman SL, Kutscher SJ, Gregory AJ, Solomon GS. Baseline neurocognitive testing in sports-related concussions: the importance of a prior night's sleep. Am J Sports Med. 2014;42(2):472-8.

McKee AC, Cantu RC, Nowinski CJ, Hedley-Whyte ET, Gavett BE, Budson AE, Santini VE, Lee HS, Kubilus CA, Stern RA. Chronic traumatic encephalopathy in athletes: progressive tauopathy after repetitive head injury. J Neuropathol Exp Neurol. 2009;68(7):709-35.

Menn SJ, Yang R, Lankford A. Armodafinil for the treatment of excessive sleepiness associated with mild or moderate closed traumatic brain injury: a 12-week, randomized, double-blind study followed by a 12-month openlabel extension. J Clin Sleep Med. 2014;10(11):1181-91.

Mignot EJ. A practical guide to the therapy of narcolepsy and hypersomnia syndromes. Neurotherapeutics. 2012;9(4):739-52.

Mihalik JP, Lengas E, Register-Mihalik JK, Oyama S, Begalle RL, Guskiewicz KM. The effects of sleep quality and sleep quantity on concussion baseline assessment. Clin J Sport Med. 2013;23(5):343-8.

Minen MT, Boubour A, Walia H, Barr W. Post-concussive syndrome: a focus on post-traumatic headache and related cognitive, psychiatric, and sleep issues. Curr Neurol Neurosci Rep. 2016;16(11):100.

Mollayeva T, Mollayeva S, Colantonio A. The risk of sleep disorder among persons with mild traumatic brain injury. Curr Neurol Neurosci Rep. 2016;16(6):55.

Mollayeva T, Mollayeva S, Shapiro CM, Cassidy JD, Colantonio A. Insomnia in workers with delayed recovery from mild traumatic brain injury. Sleep Med. 2016;19:153-61

Monti JM, Voss MW, Pence A, McAuley E, Kramer AF, Cohen NJ. History of mild traumatic brain injury is associated with deficits in relational memory, reduced hippocampal volume, and less neural activity later in life. Front Aging Neurosci. 2013;5:41.

Nagtegaal JE, Kerkhof GA, Smits MG, Swart AC, van der Meer YG. Traumatic brain injury-associated delayed sleep phase syndrome. Funct Neurol. 1997;12(6): 345-8.

Nakase-Richardson R, Sherer M, Barnett SD, et al. Prospective evaluation of the nature, course, and impact of acute sleep abnormality after traumatic brain injury. Arch Phys Med Rehabil. 2013;94(5):875-82.

Ouellet MC, Beaulieu-Bonneau S, Morin CM. Insomnia in patients with traumatic brain injury: frequency, characteristics, and risk factors. J Head Trauma Rehabil. 2006;21(3):199-212.

Ouellet MC, Beaulieu-Bonneau S, Morin CM. Sleep-wake disturbances after traumatic brain injury. Lancet Neurol. 2015;14(7):746-57.

Ouellet MC, Morin CM. Subjective and objective measures of insomnia in the context of traumatic brain injury: a preliminary study. Sleep Med. 2006;7(6):486-97.

Parcell DL, Ponsford JL, Redman JR, Rajaratnam SM. Poor sleep quality and changes in objectively recorded sleep after traumatic brain injury: a preliminary study. Arch Phys Med Rehabil. 2008;89(5):843-50.

Pillar G, Averbooch E, Katz N, Peled N, Kaufman Y, Shahar E. Prevalence and risk of sleep disturbances in adolescents after minor head injury. Pediatr Neurol. 2003;29:131-5.

Ponsford J, Draper K, Schönberger M. Functional outcome 10 years after traumatic brain injury: its relationship with demographic, injury severity, and cognitive and emotional status. J Int Neuropsychol Soc. 2008;14(2):233-42.

Poryazova R, Hug D, Baumann CR. Narcolepsy and traumatic brain injury: cause or consequence? Sleep Med. 2011;12(8):811.
Quan SF. Are sleep disturbances a risk for chronic traumatic encephalopathy? Only the shadow knows. J Clin Sleep Med. 2014;10(3):241-2.

Quinto C, Gellido C, Chokroverty S, Masdeu J. Posttraumatic delayed sleep phase syndrome. Neurology. 2000;54(1):250-2.

Raikes AC, Schaefer SY. Sleep quantity and quality during acute concussion: a pilot study. Sleep. 2016; [Epub ahead of print]

Rao V, Koliatsos V, Ahmed F, Lyketsos C, Kortte K. Neuropsychiatric disturbances associated with traumatic brain injury: a practical approach to evaluation and management. Semin Neurol. 2015;35(1):64-82.

Shekleton JA, Parcell DL, Redman JR, Phipps-Nelson J, Ponsford JL, Rajaratnam SM. Sleep disturbance and melatonin levels following traumatic brain injury. Neurology. 2010;74(21):1732-8.

Singh K, Morse AM, Tkachenko N, Kothare SV. Sleep disorders associated with traumatic brain injury-a review. Pediatr Neurol. 2016;60:30-6.

Smits MG, Nagtegaal JE. Post-traumatic delayed sleep phase syndrome. Neurology. 2000;55(6):902-3.

Sommerauer M, Valko PO, Werth E, Baumann CR. Excessive sleep need following traumatic brain injury. A case-control study of 36 patients. J Sleep Res. 2013; 22:634-9.

Sufrinko A, Pearce K, Elbin RJ, Covassin T, Johnson E, Collins M, Kontos AP. The effect of preinjury sleep difficulties on neurocognitive impairment and symptoms after sport-related concussion. Am J Sports Med. 2015:43(4):830-8.

Sumpter RE, Dorris L, Kelly T, McMillan TM. Pediatric sleep difficulties after moderatesevere traumatic brain injury. J Int Neuropsychol Soc. 2013;19(7):829-34.

Tham SW, Fales J, Palermo TM. Subjective and objective assessment of sleep in adolescents with mild traumatic brain injury. J Neurotrauma. 2015;32(11):847-52.

Tham SW, Palermo TM, Vavilala MS, Wang J, Jaffe KM, Koepsell TD, Dorsch A, Temkin N, Durbin D, Rivara FP. The longitudinal course, risk factors, and impact of sleep disturbances in children with traumatic brain injury. J Neurotrauma. 2012;29(1):154-61.

Theadom A, Starkey N, Jones K, Cropley M, Parmar P, Barker-Collo S, Feigin VL. Sleep difficulties and their impact on recovery following mild traumatic brain injury in children. Brain Inj. 2016;30(10):1243-8.

Viola-Saltzman M, Musleh C. Traumatic brain injury-induced sleep disorders. Neuropsychiatr Dis Treat. 2016;12:339-48.

Watson NF, Dikmen S, Machamer J, Doherty M, Temkin N. Hypersomnia following traumatic brain injury. J Clin Sleep Med. 2007;3:363-8.

Wickwire EM, Williams SG, Roth T, Capaldi VF, Jaffe M, Moline M, Motamedi GK, Morgan GW, Mysliwiec V, Germain A, Pazdan RM, Ferziger R, Balkin TJ, MacDonald ME, Macek TA, Yochelson MR, Scharf SM, Lettieri CJ. Sleep, sleep disorders, and mild traumatic brain injury. What we know and what we need to know: findings from a National Working Group. Neurotherapeutics. 2016;13(2):403-17.

Williams BR, Lazic SE, Ogilvie RD. Polysomnographic and quantitative EEG analysis of subjects with long-term insomnia complaints associated with mild traumatic brain injury. Clin Neurophysiol. 2008;119(2):429-38.

Zeitzer JM, Friedman L, O'Hara R. Insomnia in the context of traumatic brain injury. J Rehabil Res Dev. 2009;46(6):827-36.

\section{Submit your next manuscript to BioMed Central and we will help you at every step:}

- We accept pre-submission inquiries

- Our selector tool helps you to find the most relevant journal

- We provide round the clock customer support

- Convenient online submission

- Thorough peer review

- Inclusion in PubMed and all major indexing services

- Maximum visibility for your research

Submit your manuscript at www.biomedcentral.com/submit 